\title{
: Nuevos reflejos de la debilidad del Parlamento
}

\author{
New reflections of the weakness \\ of Parliament
}

JOSÉ TUDELA ARANDA

Letrado de las Cortes de Aragón.

Profesor de Derecho Constitucional.

Universidad de Zaragoza.

jtudela@cortesaragon.es

DOI: https://doi.org/10.7203/cc.2.22172

Fecha de recepción: 27/08/2021

Fecha de aceptación: 02/10/2021

\section{Resumen}

En este artículo se analizan los problemas que actualmente atraviesa la institución parlamentaria en España. El autor repasa los peligros que acechan, desde distintos ámbitos y sectores, al Parlamento como institución central de nuestro Estado democrático de Derecho, prestando especial atención a los efectos que sobre la misma ha tenido la crisis sanitaria global de la covid-19. Desde tales coordenadas se defiende la necesidad de que el Parlamento acometa un profundo proceso de renovación.

Palabras clave

Parlamento; funciones; COVID-19; control; democracia.

\begin{abstract}
This article analyzes the problems currently facing the parliamentary institution in Spain. The author reviews the dangers that lie in wait, from different spheres and sectors, to Parliament as the central institution of our democratic State of Law, paying special attention to the effects that the global health crisis of covid-19 has had on it. From such coordinates, the need for Parliament to undertake a profound process of renewal is defended.
\end{abstract}

\section{Keywords}

Parliament; functions; COVID-19; control; democracy. 


\section{Introducción. - II. La función legislativa. La extraña (o no tanto) normalidad del Decreto-Ley. - III. Control del Gobierno. Del Gobierno en funciones al Gobierno ausente. - IV. Señales preocupantes. El Parlamento y las líneas rojas. - V. Reflexiones para un mañana que es presente. Bibliografía.}

\section{Introducción}

Los estudios sobre el Parlamento se encuentran ensombrecidos por una mancha de pesimismo. Si bien puede aducirse que es una afirmación demasiado generalista, lo cierto es que la literatura académica viene proyectando bien de forma expresa bien de forma implícita la imagen de un Parlamento débil, en crisis (Greciet, 2012; Astarloa, 2017). Como he sostenido en otros trabajos, mi opinión se alinea con ese pesimismo. El Parlamento es hoy una institución "perdida". Con este adjetivo quiero expresar su falta de adecuación a un nuevo contexto político y social, lo que trae como consecuencia fracaso en el ejercicio de sus funciones singulares; debilidad de su función principal, la representación política; y, en consecuencia, distancia con los ciudadanos. La crisis provocada por la pandemia originada por la Covid-19 era una oportunidad para que la Institución pudiese reivindicarse $y$, hasta un cierto punto, reinventarse. Me explico. La pandemia provocó una situación social y política que requería muy especialmente del Parlamento. Se necesitaban acuerdos políticos que debían fraguarse con las características del trabajo parlamentario, deliberación y publicidad; eran precisas reformas legislativas que debían pasar por el tamiz de los órganos parlamentarios; el Gobierno adquiría, necesariamente, una dosis de poder extraordinario y, en consecuencia, su control era más importante que nunca. Pero, por encima de todo, el Parlamento debía transmitir a los ciudadanos un mínimo de confianza en las instituciones en la que, probablemente, era la crisis más grave en décadas. Si se hubiese respondido, al menos parcialmente, de acuerdo con estas exigencias, no tengo duda de que el Parlamento hubiese recuperado una parte de su prestigio perdido. Pero, creo, no ha sido así.

También es preciso explicar la alusión a la oportunidad de reinvención. Para el Parlamento, lo primero que resultó evidente es que era necesario articular una distinta forma de trabajar. Las exigencias sanitarias restringían la posibilidad de reuniones y, en consecuencia, debía arbitrar formas novedosas para poder seguir activo, aunque fuese quebrando una de sus premisas, como es la presencialidad (García Escudero, 2020: 19). En este punto, es preciso llamar la atención sobre el hecho, cuando menos sorprendente, de que se tardase en comprender el carácter esencial de la actividad parlamentaria y que durante algún tiempo, que en algunas Comunidades Autónomas fue largo, permaneciese cerrado por "razones sanitarias". Sin duda, éstas existían y obligaban a adoptar 
determinadas medidas que afectaban a la forma ordinaria de trabajo. Pero lo mismo sucedía en muchas profesiones que en ningún momento consideraron la posibilidad de parar completamente. Parece obvio pero es preciso decirlo. En un sistema democrático, en ninguna circunstancia el Parlamento puede detener su actividad. Pero se trataba de explicar la alusión a la reinvención. Pasadas las primeras semanas, se pensó cómo hacer compatible la necesaria actividad parlamentaria con las limitaciones impuestas por las características de la pandemia. La consecuencia inmediata fue arbitrar fórmulas de "teletrabajo parlamentario", extendiendo significativamente la posibilidad de votación a distancia y disminuyendo considerablemente el número de diputados presentes en los distintos órganos parlamentarios (VV.AA., 2020). Es fácil predecir que algunos de los hábitos adquiridos durante la pandemia han llegado para quedarse. Y es aquí donde emerge el significado de la expresión "reinvención". El Parlamento ha descubierto posibilidades de trabajo que deberían ayudarle a ampliar su abanico de actividad. Desarrollar esas posibilidades es un reto inmediato para la Institución. Por el contrario, debe evitarse la tentación de convertir en hábito aquello que quiebra principios esenciales.

En estas líneas preliminares, es también preciso aclarar que si bien este análisis se va a centrar en lo sucedido en las Cortes Generales y, muy especialmente, en el Congreso de los Diputados, ello no debe ocultar que la realidad parlamentaria en España sólo se puede entender desde el presupuesto de la existencia de diecisiete Parlamentos autonómicos. Por ello, añadiré una breve reflexión sobre lo que un primer análisis de lo sucedido en estos Parlamentos puede aportar a un estudio con los objetivos declarados. Y al hilo de la misma, se realizará una referencia a la reforma del Reglamento del Parlamento de Andalucía, como un síntoma más de la pérdida de referencias necesarias en la que se encuentra sumergido no sólo el modelo parlamentario sino el sistema político en su conjunto (Tudela, 2020a).

La pandemia ha sido una tormenta perfecta. También para el Parlamento. $\mathrm{Y}$ como respecto de otras muchas cosas, mayoritariamente no va a ser causa directa de cambios o debilidades. Más bien, ha sido, es, un suceso propicio para levantar el velo de insuficiencias y disfunciones acumuladas y un catalizador de cambios. Así, los datos que se pueden obtener hoy del hacer parlamentario durante la crisis deben conjugarse con la descripción tanto de las dinámicas políticas en las que se ha desenvuelto como de las características que definían al Parlamento pre crisis. Lógicamente, no es posible en estas páginas hacer el análisis exhaustivo que se requiere. Pero, en todo caso, se realizará una breve aproximación a esas dinámicas que explican en buena medida el correcto o incorrecto funcionamiento de la Institución.

Hasta que la crisis política se tradujo electoralmente en las elecciones de 2015, el sistema político había funcionado de acuerdo con la lógica parlamentaria con la que se había diseñado. El gobierno que había obtenido la confianza parlamentaria, disponía de una cómoda mayoría en el Parlamento que le permitía controlar la acción política (Paniagua, 2012). A lo sumo, había ejemplos de gobiernos que, aún minoritarios, se encontraban suficientemente cerca de la mayoría absoluta para poder jugar con el apoyo de una u otra formación en la lógica de lo que se denominó, geometría variable durante los gobiernos de José Luis Rodríguez Zapatero'. Pero la fecha señalada, todo cambió. Cinco años, cuatro elecciones generales, dos Legislaturas fallidas, una moción de censura

1 La fórmula, resultó políticamente exitosa. El Gobierno superó casi todas las votaciones, https://elpais.com/diario/2009/06/28/espana/1246140005 850215.html 
constructiva victoriosa, ninguna mayoría estable de gobierno. Todo ello ha tenido profundas consecuencias sobre el desenvolvimiento de nuestra forma de gobierno (VV.AA., 2017). En las Comunidades Autónomas, si bien la situación ha sido sustancialmente más estable (no se han producido legislaturas fallidas y los gobiernos han acabado con normalidad sus mandatos), también han abundado los gobiernos en minoría (Guillén, 2019: 83-84). Algunos han visto en este tiempo, la recuperación del protagonismo político por el Parlamento. En mi opinión, ese protagonismo ha sido más efectista que efectivo. Por el contrario, se ha producido una grave distorsión del régimen parlamentario, hasta el extremo de poder calificarse como perversión. En un sistema parlamentario, por definición, el gobierno debe sustentarse en una mayoría parlamentaria estable. Si no es así, si se gobierna en minoría, se trata de una disfunción del sistema. La necesaria recuperación política del Parlamento no puede traducirse en que asuma la dirección política, al modo de un régimen asambleario (Aragón, 2017: 29-31). No ha sucedido esto. Pero tampoco el Gobierno dispone de una mayoría parlamentaria suficiente como para ejecutar sus políticas como correspondería a la ortodoxia del sistema parlamentario. Reflejo de ello es la reiterada utilización del Decreto-Ley o la prórroga por seis meses del segundo estado de alarma ${ }^{2}$. En todo caso, se trata de una grave distorsión del sistema. Una distorsión que tiene causa tanto en una objetiva compleja composición de las Cámaras como en la dificultad de las formaciones políticas para alcanzar un mínimo sustrato de acuerdo que facilitase un gobierno estable. Mas, con todo, la experiencia ha demostrado que incluso en este marco político, el protagonismo del Parlamento es reducido. Ejemplo elocuente de ello es lo sucedido durante la pandemia, periodo en el que el rol del Parlamento ha sido casi irrelevante.

La realidad política española exige una acotación adicional. He denunciado la anormalidad que supone la incapacidad para conformar una mayoría estable de gobierno. Incluso para aproximarse a la misma. $Y$ he señalado que sin la misma es muy difícil que un sistema político basado en una forma de gobierno parlamentaria puede desempeñarse con eficacia y ortodoxia constitucional. Una reflexión que aplicada al caso español y a lo sucedido en los últimos años, implica que, en mi parecer, la mencionada ausencia de mayorías sea una de las causas principales de los muy graves déficits de funcionamiento de nuestro sistema. Ahora bien, para disponer de una imagen más completa, es preciso dar un paso más y subrayar cómo la actual composición de las Cámaras dificulta extraordinariamente ese objetivo. La fuerte presencia de partidos independentistas y/o situados a ambos extremos del arco parlamentario, restringe sobremanera las posibilidades de una mayoría coherente con el actual sistema constitucional. De hecho, lo hace casi imposible a salvo de un hipotético y, por lo que se ha visto hasta ahora, imposible, acuerdo entre los dos principales partidos.

El sistema político no sólo se ha fragmentado. Se ha polarizado de forma extrema. Hace diez años, la presencia de fuerzas radicales, en uno u otro sentido, era extremadamente minoritaria. Hoy, superan los cien escaños. Necesariamente, su influencia es decisiva. No sólo por lo que suponen en sí mismas. También por la radicalización a la que llevan a los dos grandes partidos que ven temer parte de su electorado. Lógicamente, ello afecta al trabajo en el Parlamento. El Parlamento es deliberación y adopción de las decisiones por mayoría. Por

2 Creo que es claro que si el Gobierno hubiese dispuesto de una mayoría estable en el Congreso de los Diputados se hubiese limitado a seguir la pauta de la prórroga por quince días. La explicación de una decisión tan poco "ortodoxa" como extender la prórroga a seis meses sólo se puede vincular a la extrema dificultad que para alcanzar las mayorías necesarias depara la actual composición del Congreso de los Diputados. 
supuesto, no se trata de buscar unanimidades ni siquiera consensos generalizados. Pero en el ethos de la Institución está el ser locus del acuerdo. Al menos, de acuerdos esenciales en las grandes materias. La actual composición del Parlamento español y, es preciso repetirlo, la actitud de los dos grandes partidos, hace imposible que se logren esos acuerdos. Por otro lado, la consecución de las mayorías necesarias para sacar a delante las propuestas gubernamentales es también una operación compleja, con costes diversos. El Gobierno busca evitar el Parlamento; los debates derivan en broncas rudimentarias; la oposición no logra medir el sentido del control. Por lo demás, la labor de los órganos rectores de las Cámaras no ayuda. Lejos de buscar el espacio adecuado para la Institución, se han limitado a procurar hacer realidad las necesidades del gobierno. Así, es sencillo explicar por qué lejos de aprovechar la oportunidad, el Congreso ha vuelto a evidenciar sus debilidades. Una situación que no puede considerarse de forma aislada sino que exige su inserción en un examen global del funcionamiento de nuestro sistema político.

Una conclusión relevante que puede extraerse de lo expuesto es que resulta preciso buscar el protagonismo del Parlamento de forma coherente con el funcionamiento racional del modelo parlamentario establecido en la Constitución. Y en ese modelo, los gobiernos sostenidos por una minoría alejada de la mayoría, con necesidad de arduas y complejas negociaciones para conseguir la mayoría necesaria en cada votación, son una anomalía. Una anomalía incoherente con el modelo y, por todo, les conduce a estar necesariamente abocados al fracaso o a producir muy negativas consecuencias. Hay que vindicar y fortalecer el Parlamento en la dinámica ordinaria del régimen parlamentario. Cumpliendo, por tanto, las funciones que le corresponden. Cumpliéndolas, eso sí, con la efectividad y eficacia necesarias.

\section{La función legislativa. La extraña (o no tanto) normalidad del Decreto-Ley}

Si se analiza la actividad de un Parlamento, es forzoso fijarse en la función legislativa, una de sus dos funciones principales y, en todo caso, la de mayor carga simbólica. El estudio del ejercicio de la función legislativa en un Parlamento se puede hacer, y se ha hecho con profusión, desde perspectivas muy diferentes. Dejando de lado el estudio de la naturaleza de la ley, se pueden analizar cuestiones como la regulación del procedimiento legislativo y sus consecuencias; la calidad técnica de las leyes aprobadas; el número y clase de leyes aprobadas, o, entre otras, la distribución de las mismas según su iniciativa. Todas son cuestiones significativas. Pero en los últimos años, en general, han sido postergadas por la "normalización" del Decreto-Ley (Carmona, 1997; Aragón, 2016). Una norma que si bien había sido utilizada con frecuencia excesiva por todos los gobiernos de la democracia, ha pasado en la última década a, sin exageración alguna, protagonizar la función legislativa del Parlamento, hasta el extremo de transcender los análisis académicos para ser objeto de reflexión cotidiana $^{3}$. Una expansión, resulta preciso señalarlo, a la que contribuyó una doctrina "permisiva" del Tribunal Constitucional. Hoy, como se verá, se aprueba un número significativamente mayor de decretos-leyes que de leyes. Y si bien se pueden apreciar circunstancias coyunturales que ayudan a explicar este

3 Por todos, este artículo de Ignacio Varela publicado en El Confidencial el 14 de abril de 2021: https://blogs.elconfidencial.com/espana/una-cierta-mirada/2021-04-14

pandemia-pretexto-alarma-estado-derecho 3033064 
hecho, hay elementos suficientes para poder intuir un cambio estructural. Hace tiempo que el estudio de la actualidad del Decreto-Ley transciende el análisis de una norma en concreto. En mi opinión, hoy se relaciona directamente con la esencia de la función legislativa y con la necesaria reformulación de ésta. Se trata de un fenómeno complejo en el que confluye la necesidad propiciada por un nuevo modelo social; circunstancias políticas como las descritas; 0 , desde luego, malos hábitos políticos. Factores coyunturales y factores estructurales que se entrecruzan hasta distorsionar severamente una de las funciones principales del Parlamento.

No hay exageración en estas palabras. Las cifras hablan por sí solas. Si la crisis económica de 2008 produjo una primera eclosión del uso de esta figura, la verdadera transformación de su rol constitucional sucede en el marco del Parlamento fragmentado y, más en concreto, con la sucesión de gobiernos sin el apoyo de una mayoría parlamentaria estable. Es decir, a partir de la $X$ Legislatura. Desde entonces, recuérdese, dos Legislatura fallidas (XI y XIII), una que se escinde en dos gobiernos con mayorías minoritarias bien diferentes (la XII) y otra con Gobierno minoritario (la XIV). Para lo que estas líneas quieren ilustrar, nos serviremos de lo sucedido en la XII y en la XIV. Si bien es cierto que en ambas concurren circunstancias extraordinarias (éxito de una moción de censura y pandemia, respectivamente), no dejan de ser ilustrativas de la deriva de la función legislativa.

Por primera vez en la reciente historia de España, una Legislatura escindió su tiempo entre dos gobiernos de signo opuesto. Una primera etapa, desde el 19 de julio de 2016 hasta el 1 de junio de 2018, ostentó la Presidencia el líder del Partido Popular, Mariano Rajoy con el apoyo de 170 Diputados. Desde el triunfo de la moción de censura, hasta el 5 de marzo de 2019, el Gobierno fue presidido por el líder del PSOE, Pedro Sánchez con un apoyo parlamentario de 151 Diputados. Uno y otro Gobierno tuvieron serias dificultades para obtener las mayorías necesarias en el Congreso para aprobar sus iniciativas. El resultado fue que durante la misma se tramitaron 49 proyectos de ley y 65 decretos leyes. Lo excepcional se había convertido, con generosidad, en lo habitual. También es significativo el reparto entre los dos periodos. El Gobierno de Mariano Rajoy remitió en 22 meses, 30 decretos leyes. El Gobierno presidido por Pedro Sánchez, en 9 meses, 35. Todos los decretos leyes, menos uno aprobado por el Gobierno de Mariano Rajoy, fueron convalidados. Pero para tener una cabal idea de lo que significan estas cifras, hay que volver a los proyectos de ley. De los 23 que presentó el Gobierno de Mariano Rajoy, fueron aprobados 17 y 6 caducaron o se retiraron. Por su parte, el Gobierno de Pedro Sánchez presentó hasta 32 proyectos, aprobándose sólo cuatro.

El balance de la XIV Legislatura debe realizarse con más cautela tanto por el relativamente escaso tiempo transcurrido cuando se escriben estas líneas (apenas 20 meses) como por el hecho de que la mayoría de ese tiempo ha sido dominado por una circunstancia extraordinaria como la pandemia que puede explicar razonablemente una parte del recurso al Decreto-Ley. Pero, de nuevo, el hecho esencial para comprender el desenvolvimiento de la función legislativa en las Cortes Generales va a ser la composición del Congreso y la correspondiente posición inestable de un Gobierno asentado sobre una mayoría conformada por 155 Diputados. En estas circunstancias, hasta el 1 de agosto de 2021, se han aprobado un total de 55 decretos leyes y 33 leyes.

Éstas y otras cifras reflejan bien como la anomalía se ha convertido en regla. Así, en relación con la función legislativa se puede apreciar como el DecretoLey sustituye a la iniciativa legislativa ordinaria como instrumento preferente del Gobierno para legislar. 
En conjunto, la preeminencia del Decreto-Ley supone un paso más en el desapoderamiento del Parlamento en el conjunto de la función legislativa. Así, alguno podría llegar a decir que el cambio no es tan relevante. En un Parlamento con mayoría gubernamental estable, la ley es la que el gobierno desea que sea. También en ese caso el protagonismo de la Institución parlamentaria es muy relativo. Ello es así y por ello mismo es ya tradicional considerar que la actividad nuclear del Parlamento contemporáneo es el control. Pero la sustitución del ejercicio ordinario de la función legislativa por el dominio del Decreto-Ley representa un cambio cualitativo de indudable transcendencia. Supone el desapoderamiento del Parlamento de una parte significativa de su esencia en una función primordial. Por más que el gobierno pudiese imponer un criterio, se veía obligado a sustanciar distintos trámites parlamentarios y los distintos grupos parlamentarios, no sólo de oposición, tenían la opción de modular el texto gubernamental. También podían expresar su opinión final con matices, sin necesidad de tener que optar por un apoyo o un rechazo global. Todo ello es sabido y no es preciso insistir. Sí es necesario hacerlo sobre lo que de desparlamentarización de la vida política tiene el hecho de que el Decreto-Ley se convierta en la forma habitual de legislar.

El abuso de la figura del Decreto-Ley ha sido similar en el Estado y en las Comunidades Autónomas que disponen de esta fuente en su ordenamiento. Aunque es mayoritario el pensar que en el ámbito autonómico este instrumento es superfluo, políticamente resultaba inevitable la mímesis, cuando las Comunidades Autónomas han replicado todo el sistema institucional del Estado. Y similar sea cual sea la formación política que ostentaba el correspondiente Gobierno. Lo cual, no es ocioso señalarlo, resulta una ventaja para su análisis. No sólo porque la generalización de rasgos facilita la obtención de conclusiones. También porque las limpia, las debería limpiar, del óxido contaminante que para el análisis científico es la lucha partidista.

Como he indicado, la suma de una serie de circunstancias que pueden considerarse coyunturales (crisis económica; ausencia de mayorías parlamentarias; pandemia), son factores objetivos que explican y, en algunos casos, incluso justifican siquiera parcialmente, la utilización del Decreto-Ley. Pero, en mi opinión, junto a estas razones circunstanciales subyacen otras más profundas. Razones que llegan a afectar al ser de la Institución parlamentaria, al poner en tela de juicio su capacidad en relación con una de sus funciones esenciales. Es por ello, por lo que entiendo preciso no desvincular esta circunstancia de la situación general en la que se encuentra la Institución.

Cualquier conocedor del Derecho constitucional sabe que el Decreto-Ley es una fuente extraordinaria del ordenamiento. Extraordinaria porque altera el reparto de funciones entre poder legislativo y poder ejecutivo. Su presupuesto inexcusable, la existencia de "extraordinaria y urgente necesidad". Dos adjetivos que no se superponían, se trataban de circunstancias que debían confluir, redundando en el carácter excepcional de esta fuente del derecho. Hasta fechas casi inmediatas, el debate académico, y jurisprudencial, sobre el Decreto-Ley se ha centrado en el alcance de esos adjetivos y, secundariamente, en la definición de las materias que tenía reservadas. Creo que seguir poniendo el foco en ello, es velar por las cuestiones principales que pone de manifiesto el generalizado abuso que se realiza de su uso. Su importancia es evidente. Tanta que de su enjuiciamiento dependerá la constitucionalidad o no de un determinado texto. Pero cuando en una Legislatura se aprueba un número de decretos-leyes que duplica al de las leyes; cuando el fenómeno no sólo se mantiene sino que se incrementa cada año allí donde existe la figura; y cuando todos somos conscientes de que son numerosos los textos que permanecen en vigor con dudas 
más que razonables sobre la existencia del presupuesto habilitante, parece conveniente intentar levantar la pátina de la apariencia, para aproximarse a cuestiones más estructurales.

El tradicional mal uso del Decreto-Ley se ha incrementado sustancialmente en los últimos años por razones profundas y que afectan a la estructura del sistema político y constitucional. Aunque podrían mencionarse algunas más, destacaré las tres que estimo principales. En primer lugar, la crisis de la ley como fuente ordinaria del Derecho y expresión de la dirección política de una comunidad. En segundo lugar, un cambio en el sistema de partidos y, en consecuencia, en la gobernabilidad del Estado a la que los actores no han sabido reaccionar. En tercer lugar, la débil cultura institucional que muestra la política española. Me extenderé mínimamente sobre estas cuestiones.

No se reflexiona suficientemente sobre la ley. Se insiste en problemas como una defectuosa técnica legislativa; los cambios constantes en la legislación o la ineficacia de muchas normas. Pero no se pregunta, no al menos con la necesaria insistencia, por las razones que provocan que podamos definir los anteriores rasgos, y otros que podrían citarse, como estructurales. Creo que, al margen de problemas coyunturales, todos ellos se encuentran en la dificultad de adaptar la forma de elaboración, estructura y lenguaje de las leyes tradicionales, al nuevo contexto social, económico y tecnológico. El recurso al Decreto-Ley es, al menos en ocasiones, la respuesta que se encuentra a las objetivas dificultades que plantea el ejercicio natural de su iniciativa legislativa (Tudela, 2020b: 21-48).

Las razones de las dificultades por las que atraviesa la ley y, en general, el ejercicio de la función legislativa, son múltiples. Pero entre ellas es posible destacar un hecho esencial: la aceleración del tiempo y su necesaria repercusión en el Derecho. La vocación de permanencia es innata a la norma jurídica, condición de eficacia e, incluso, de legitimidad. No en vano su formulación moderna se encuentra vinculada al sueño de la razón. De una razón capaz de transformar la realidad. Para que ello fuese posible, condición necesaria es que esa realidad sea esencialmente estable. $Y$ así ha sido durante mucho tiempo. Y cuando no lo ha sido, el Derecho se ha enfrentado a crisis de inoperancia. En tiempos convulsos, de transformaciones radicales, la realidad no se rige por el Derecho. Hoy, nuestro tiempo se caracteriza por presupuestos contrarios a las premisas exigidas por las características de la ley clásica. La provisionalidad se ha convertido en estado, de casi nada se puede asegurar una mínima pervivencia en el tiempo. Responder a los retos que esta circunstancia plantea es tan necesario como complejo.

El cambio en el sistema político bien podría mencionarse como una circunstancia coyuntural. Aún si así fuese, merecería un comentario por su transcendencia más allá del propio recurso al Decreto-Ley. Pero si la menciono en este punto es porque creo que tiene un vínculo profundo con el mencionado cambio social. Las circunstancias políticas son hoy particularmente volátiles. Es posible que en un tiempo cercano se pueda llegar a conformar una mayoría parlamentaria aparentemente estable. Pero nadie podrá garantizar que la estabilidad ha regresado como característica de nuestro sistema político. Además, es previsible que durante un periodo relativamente largo, cualquier mayoría dependa de fuerzas políticas radicales, si no directamente situadas fuera del sistema político. Todo ello me ratifica en la idea de que la estabilidad como presupuesto de un ortodoxo ejercicio de la función legislativa está hoy más cerca del pasado que del presente y futuro inmediato En estas circunstancias, necesariamente, el Decreto-Ley adquiere una nueva dimensión que lo aleja sustancialmente de sus orígenes y que llega a afectar al nervio de la forma de gobierno. Deja de ser una norma que responde estrictamente a la necesidad del 
gobierno de dar una respuesta con valor de ley a circunstancias extraordinarias para ser un instrumento del gobierno para evadir su debilidad en el Parlamento.

En todo caso, el abuso y mal uso del Decreto-Ley transciende la mayoría que pueda sustentar a un gobierno. La mera comodidad y el desdén por los trámites parlamentarios lo alimentan allí donde sí existe esa mayoría. No es sino un reflejo más de cómo, en demasiadas ocasiones, líderes y partidos se relacionan con el orden institucional. Y es que la crisis de la función legislativa y la deficiente utilización del Decreto-Ley, no son hechos aislados. Deben insertarse en un severo deterioro del sistema institucional. Casi todas las instituciones y las categorías más relevantes del sistema constitucional han sido castigadas en los últimos años por lo que al menos se puede calificar como irresponsable comportamiento de las fuerzas políticas, sin excepción alguna en este punto. Poco a poco se han ido traspasando presumibles líneas rojas hasta llegar al extremo de insertar en la normalidad hechos que en cualquier otro momento hubiesen sido causa de razonable escándalo. Como siempre, las explicaciones son múltiples. Cualquier reduccionismo es una simpleza excesiva para un fenómeno particularmente relevante. Pero es difícil no ver en la débil cultura institucional de nuestros actores políticos una de las más relevantes. Un hecho necesariamente agravado en tiempos de confusión política. Los ejemplos se multiplican. No es preciso más que observar la situación de los distintos órganos constitucionales para darse cuenta de la gravedad del fenómeno. La situación ha transcendido la preocupación académica para formar parte del debate social. Si los distintos actores políticos no toman conciencia de la gravedad de la situación y de sus consecuencias, no habrá solución. Como indiqué, en relación con el Decreto-Ley y, en general, con el desempeño de la función legislativa, no será suficiente. Pero sí es una condición indispensable. Precisamente, la relevancia de los cambios sociales acaecidos durante los últimos años y que son causa necesaria de disfunciones institucionales, obliga a multiplicar la prudencia y el sentido de Estado. Sucede lo contrario. Las distintas fuerzas políticas se suben con entusiasmo a las peores corrientes y acaban convirtiéndose en agentes de corrosión en vez de cumplir el papel que les corresponde. Es forzoso insistir en este particular. La erosión del sistema institucional tiene muy graves consecuencias. Las gotas erosionan el suelo y éste, un día inesperado, cede.

La reflexión sobre el Decreto-Ley debe finalizar con una doble consideración. Por un lado, resulta preciso llamar la atención sobre la gravedad del hecho de su conversión en la fuente ordinaria del ejercicio de la función legislativa. De esta manera, se facilita el gobierno en ausencia de mayoría parlamentaria y se acaba consagrando una situación que cabe calificar como de anormalidad constitucional. Una forma parlamentaria exige la existencia de mayorías de gobierno estables. Si acaba siendo norma lo contrario, gobiernos sostenidos por minorías alejadas de esa estabilidad y, por tanto, necesariamente reacias a gobernar con el Parlamento, la forma de gobierno se adultera. Lo relevante del caso español es que la dificultad (objetiva y subjetiva) para lograr esa estabilidad, invita a pensar que lo que en un principio se pensó pudiese ser una circunstancia coyuntural, se acabe convirtiendo en rasgo estructural del sistema $y$, por tanto, en un virus infeccioso de consecuencias imprevisibles.

Junto a lo anterior, hay que regresar a las corrientes subyacentes a la explosión del Decreto-Ley. Como indiqué, particular relevancia tiene la aceleración del ritmo de los cambios sociales. La relación entre el tiempo y el derecho ha mutado y lo ha hecho de forma que se alteran presupuestos clásicos y esenciales de nuestra comprensión del ordenamiento jurídico. En relación con el Decreto-Ley, bien puede decirse que hoy lo extraordinario es ordinario. Se vive en lo "extraordinario". Sólo hay que ver la velocidad con la que temas y datos 
desaparecen para ser sustituidos por otros igual de contingentes, pero, también, igual de extraordinarios, en los dos sentidos del término. Así las cosas, la apelación al Decreto-Ley se convierte en ocasiones en la única, al menos el más eficaz, instrumento con el que cuenta el poder público para hacer frente a determinadas situaciones.

No es posible negar que la "normalización" del Decreto-Ley es una grave anomalía constitucional. Como he querido explicar, las causas son diversas y se deben tanto a defectuosas prácticas políticas como a circunstancias más complejas que transcienden a esta fuente del Derecho. La reflexión sobre el Decreto-Ley debe insertarse hoy en un debate más amplio sobre la ley en la que se planteen nuevas líneas de trabajo y/o una nueva utilización de instrumentos ya existentes como la ley de bases o algunos procedimientos legislativos especiales (García Rocha, 2020). Hasta que ello suceda, hay que exigir de los distintos sujetos políticos una mayor responsabilidad en el uso de una fuente del derecho que es en si misma y en todo caso, una relevante distorsión del sistema. Mientras los distintos partidos no se avengan a la práctica de la autocontención, sólo quedará confiar en que el Tribunal Constitucional rectifique su tradicional complacencia con su uso para establecer criterios más rígidos al respecto ${ }^{4}$.

\section{Control del Gobierno. Del Gobierno en funciones al Gobierno ausente}

La relación entre las Cortes Generales y el poder ejecutivo en relación con la función de control ya había pasado por una situación que bien puede calificarse a la par de extraordinaria e insólita. Me refiero, lógicamente, a la negativa del Gobierno en funciones de Mariano Rajoy a ser controlado por el Parlamento por el hecho de estar "en funciones" (Ripollés, 2017: 171-174). Como es sabido, este planteamiento contradecía todos los presupuestos teóricos comúnmente aceptados hasta ese momento. Desde su constitución, Congreso y Senado se encuentran en plenitud de facultades (Aragón, 2017: 24-25; Visiedo, 2017: 198202). Una plenitud evidente en el ámbito de su autoorganización, pero también en el ejercicio de sus funciones naturales, siempre que no resulten restringidas... por las limitaciones derivadas de la existencia de un gobierno en funciones. Una situación que no había planteado problema alguno, dados los automatismos con los que había funcionado el sistema político constitucional. Pero, de nuevo, todo cambió con la mutación del sistema político. Así, y en relación con la función de control, una concreta circunstancia, la extensión de la situación provisional del Gobierno por un año (desde el 26 de octubre de 2015 hasta el 29 de octubre de 2016), suscitó una controversia política y jurídica inimaginable hasta ese momento. No me extenderé en este punto (VV.AA., 2017). Sólo recordaré que el Gobierno se negó a atender distintos requerimientos del Congreso en ejercicio de la función de control y que ello provocó la interposición por el Congreso de un conflicto de competencias al Gobierno en decisión del Pleno de 6 de abril de 2016. Para entender en toda su dimensión lo sorprendente del caso, hay que señalar que en el inicio de la Legislatura, sendos informes de las Secretarías Generales de las Cámaras, asumían la ruptura de la relación de confianza entre el Parlamento y un gobierno en funciones, lo que provocaba

4 En este sentido, puede interpretarse la STC 124/2021, de 3 de junio recaída sobre la Disposición Final Segunda del Decreto-Ley 8/2020 de 17 de marzo, de medidas urgentes extraordinarias para hacer frente al impacto económico y social del Covid-19. 
que se excluyese la posibilidad de la responsabilidad política y se entendiese que, excepcionalmente, el ejercicio de la función de control debía limitarse a las funciones residuales que podía ejercer el Gobierno. El problema radicaba en que éste negaba que, incluso, respecto de estas funciones residuales, el Parlamento pudiese ejercer control alguno.

La cuestión jurídica de fondo ha sido sobradamente estudiada (García Roca, 2017: 131-150; Reviriego, 2017: 151-176), y prácticamente resuelta con la Sentencia del Tribunal Constitucional de 14 de noviembre de 2018, estimando el conflicto de competencias planteado por el Congreso. De acuerdo con la misma, el Gobierno, al negar que el Congreso pudiese ejercer labor de control entre otras la comparecencia en la Comisión de Defensa cuya negativa fue origen del conflicto, menoscabó la función constitucional de control prevista en el 66.2. La Sentencia concluía recordando que la actuación de los dos órganos constitucionales, Gobierno y Cortes Generales deberían ejercerse "de acuerdo con el principio de lealtad institucional que ha de presidir las relaciones entre los órganos constitucionales".

Si traigo a colación este suceso, que hoy puede parecer muy lejano, es porque creo que vuelve a ser manifestación evidente de nuestra cultura política. Más, de su peligrosa deriva. Y porque es un innegable precedente de la situación que se ha generado en las relaciones Gobierno/Parlamento alrededor de la pandemia, como inmediatamente intentaré explicar. No hay síntoma más elocuente de que se trata de una enfermedad que ha infectado a todo el sistema que el hecho de que los actores políticos se inviertan. Si entonces fue un Gobierno del Partido Popular quién erosionó severamente el ejercicio de las funciones parlamentarias, durante la pandemia ha sido un Gobierno del Partido Socialista. Si se analizase lo sucedido en las distintas Comunidades Autónomas, encontraríamos más argumentos para ratificar esta tesis. Los distintos gobiernos desdeñan el hacer parlamentario, con independencia de quién se encuentre al frente.

A continuación, realizaré un breve análisis del desenvolvimiento de la función de control por el Congreso de los Diputados durante la pandemia. Lo sucedido con el Gobierno en funciones de Mariano Rajoy sirve perfectamente de síntesis conceptual. No es sencillo que un gobierno acepte con normalidad el ejercicio de la función de control, incluyendo aquellos momentos en los que ésta les puede resultar más desagradable. Que directamente o a través de su Grupo Parlamentario trate de obstaculizar su ejercicio entra dentro de las pautas de la normalidad democrática. Durante muchos años, nuestro sistema se desenvolvió en esa normalidad, si bien en demasiadas ocasiones la actuación de la mayoría llegó a suponer un lastre excesivo para un adecuado ejercicio de la función. Pero todo se desenvolvía en el margen de la anormalidad "normal", en el margen de las disfunciones asumidas y aceptadas por todo ordenamiento. Es esta línea roja la que se rompió cuando el Gobierno de Rajoy se negó a ser controlado y es la que se ha roto durante la pandemia. Con un denominador común que es preciso subrayar desde el primer momento. En ambos casos, el Gobierno se encontraba en una situación que exigía un mayor control. En un supuesto, precisamente, por encontrarse en funciones; en otra, por haber acumulado los poderes propios de un estado de alarma, amén de por especial gravedad de la situación.

En estas páginas, me voy a centrar en aspectos que bien pueden considerarse secundarios. La razón fundamental es que las cuestiones más relevantes han sido sobradamente tratadas, especialmente la prórroga de seis meses, aunque sobre este extremo realizaré una breve referencia (Garrido, 2021). Pero también porque las considero significativas de lo que se quiere denunciar en estas páginas. En todo caso, es preciso recordar la premisa de que cualquier 
situación de excepción implica en un sistema constitucional el reforzamiento de los poderes del Parlamento. Y así lo entendió nuestro constituyente. Así, el párrafo $5^{\circ}$ del artículo 116 de la Constitución bien puede considerarse como una cláusula de garantía del poder legislativo frente a la acción del ejecutivo en cualquiera de los estados de excepción. Al respecto, es preciso destacar que en el mismo se establecen dos significativas premisas. Por la primera, se impide al Gobierno disolver el Congreso estando vigentes cualesquiera de estos estados. Por la segunda, se impone la necesidad de actividad. Declarado cualquiera de ellos, las Cámaras quedarán inmediatamente convocadas si estuvieran fuera del periodo de sesiones y su funcionamiento no podrá ser interrumpido. En el caso de que el Congreso estuviese disuelto, se hace previsión expresa de que sus competencias serán ejercidas por la Diputación Permanente. Es la lógica de la democracia constitucional. A más poder, más control.

Tan sólo un breve apunte sobre la prórroga de seis meses. Como he indicado, no voy a analizar las dudas que plantea su constitucionalidad, que en mi parecer son muy importantes. Tan sólo quiero relacionar este plazo con la función constitucional que cabía esperar del Congreso durante la vigencia del segundo estado de alarma. Es difícil negar que si tuvo alguna relevancia durante el primero, fue por la necesidad de votar las sucesivas prórrogas. Cada una de ellas originó un intenso debate parlamentario. Hay que regresar a lo evidente. A lo que el debate parlamentario tiene de requisito para un adecuado funcionamiento de la democracia (Rico, 2013). En el debate, el gobierno plantea las razones que le impulsan a adoptar una determinada medida y la oposición las cuestiona y, en teoría, plantea sus alternativas. Todo ello se realiza con la máxima publicidad y con el pluralismo innato a la Institución. De esta manera, se coadyuva decisivamente a conformar la opinión pública. Durante los seis meses del segundo estado de alarma, no hubo ocasión al debate. Tan sólo algún sucedáneo devaluado. Y pocos. Así, más allá de las dudas estrictamente jurídicas, es claro que un plazo tan largo de prórroga afectó seriamente a la posición institucional del Congreso. En mi opinión, un argumento esencial para entender las dudas de constitucionalidad que plantea. También sorprende que salvo Vox, ningún Grupo Parlamentario votase en contra. Como sorprende que desde los órganos rectores de la Cámara no se realizase ninguna acción al respecto. Puede decirse que el desapoderamiento del Parlamento contó con la aquiescencia más o menos activa de la gran mayoría de sus protagonistas.

Este último dato se vincula directamente con la primera de esas cuestiones "menores" que tan significativas resultan como síntoma de la debilidad creciente de la Institución. Como es sabido, de forma súbita, el país se vio obligado a detenerse. La declaración del primer estado de alarma implicaba un confinamiento general de la población, con las lógicas repercusiones sobre la actividad general. A ello debía sumarse la oscuridad de las primeras semanas en las que una moderna peste parecía avanzar sin control. Lógicamente, el miedo y la confusión se apoderaron de muchos. Pero no todas las actividades podían detenerse. Los denominados "servicios esenciales" debían mantenerse plenamente activos.

Pues bien, sorprende que el Parlamento, en este caso los distintos Parlamentos españoles, no se considerasen desde el primer momento, servicio esencial. No lo hicieron y por un periodo más o menos largo de tiempo, su actividad se redujo a mínimos, llegando en algunos casos a "cerrar", literalmente. Una decisión que si bien puede comprenderse por las circunstancias que rodearon los primeros momentos, no deja de ser significativa (García Escudero, 2020: 20-22). Por supuesto, su función constitucional aconsejaba, si no obligaba a una determinada actividad. Pero, además, también había un elemento de ejemplaridad 
pública, mostrar a los ciudadanos la necesidad del Parlamento, solidarizarse con aquellos que no podían quedarse en casa. El Congreso llegó a autorizar el voto telemático a todos aquellos Diputados que quisieran ejercerlo. Es evidente que las Cámaras tenían que adoptar las medidas necesarias para preservar la salud de Diputados y personal. Pero la imagen que se obtiene de lo sucedido, de las sucesivas sesiones del Pleno con el hemiciclo casi vacío, no es positiva. El trabajo parlamentario es esencial por definición. Por ello, y desde la premisa de la necesidad de actuar con la necesaria cautela, hubiese sido conveniente que, actuando en coherencia, se transmitiese a los ciudadanos esa condición. No se hizo, redundando en la idea que también se transmite de la actuación de la Cámara en relación con la prórroga de los seis meses. Los parlamentarios no se valoran suficientemente. El Parlamento es una abstracción. A la postre, no es sino lo que sus miembros quieren que sea. Y de forma acumulativa demuestran que no acaban de entender el significado y transcendencia de su condición.

También merece una reflexión el papel de la oposición y el juicio que el mismo merece y ha merecido durante estos meses. Debo advertir que las líneas que siguen no se refieren a lo que ha hecho o dejado de hacer la oposición durante este tiempo. Es un juicio abstracto sobre lo que corresponde hacer a la oposición y lo que cabe esperar de la misma. El Parlamento es el hacer de la mayoría y el hacer de la oposición. Así, es preciso tener una imagen clara de cuál es el rol que la segunda debe desempeñar para poder aproximarse a un juicio completo de la Institución. Por supuesto, las muy particulares circunstancias de la pandemia deben ser tomadas en consideración. Precisamente, son las que creo que acaban de iluminar esta cuestión. El control, la crítica rigurosa, no puede verse como un obstáculo indeseable sino como una cualidad del sistema. En ello hay acuerdo, por lo que no merece la pena detenerse en este extremo. La parada viene dada porque durante los meses de la pandemia, en particular durante el primer estado de alarma, se extendieron consideraciones críticas sobre un hacer de la oposición que se consideraba "destructivo" y, por tanto, particularmente dañino en esas circunstancias. En algunos casos, se llegaba a adoptar posturas comprensibles con posibles acciones que amortiguasen su expresión y publicidad. Quién alega que el problema es que la crítica no es ni rigurosa ni constructiva, puede llegar a tener razón en la descripción. Pero ello nunca es argumento suficiente para intentar reducir su campo de acción. Quienes sostienen estas tesis ignoran una vertiente fundamental del ejercicio de la función parlamentaria de control. Mediante la misma, la oposición critica al gobierno. Pero, a su vez, se somete al escrutinio de la opinión pública. Si objetivamente se ha realizado una crítica inconveniente, destructiva, los ciudadanos actuarán en consecuencia, sancionando semejante conducta. Lo esencial es que puedan formarse opinión tanto sobre lo que realmente sucede como sobre cuál es el parecer de sus representantes al respecto. El ejercicio de la oposición también es controlado por quienes tienen la última palabra en el juicio político, los ciudadanos. La acción de la oposición puede ser errónea o, incluso, irresponsable. Como la del Gobierno. El Parlamento es el foro por excelencia para que unos y otros se muestren. Enjuiciar el trabajo de cada cual sólo corresponde a los ciudadanos.

Un extremo particularmente relevante de las relaciones entre el Gobierno y el Parlamento, y sobre el que se ha llamado menos la atención, es el relativo a la concepción que del control parlamentario subyace en el texto del segundo estado de alarma y que fue aceptado por todos los Grupos, así como, una vez más por los órganos rectores de la Cámara. En concreto, me refiero a lo que el Real Decreto de 976/2020, y la solicitud de prórroga correspondiente, denominan "Rendición de cuentas", a la que se dedica el artículo 14. En la redacción 
del Real Decreto, el artículo citado se limitaba a señalar que "en caso de prórroga, el Ministro de Sanidad comparecerá quincenalmente ante la Comisión de Sanidad y Consumo del Congreso de los Diputados para dar cuenta de la aplicación de las medidas previstas en este real decreto". Este artículo fue uno de los que se enmendó en el Congreso, como contrapartida para obtener el voto favorable de alguno de los grupos de la oposición. En su redacción final, se establece en mensual el plazo de las comparecencias del Ministro y se fija que cada dos meses el Presidente del Gobierno solicitará la comparecencia ante el Congreso de los Diputados "para dar cuenta de los datos y gestiones del Gobierno de España en relación a la aplicación del Estado de Alarma". Me parece una secuencia significativa que ayuda a comprender y valorar el papel del Congreso en la crisis.

En mi opinión, no se ha llegado a reparar suficientemente en el alcance de la redacción originaria. Más allá de la suficiencia o insuficiencia de su contenido, lo que llama poderosamente la atención es que el Gobierno se arrogue la capacidad de determinar cuándo y dónde comparecerá el Ministro. Ello sólo puede explicarse por el error de confundir la función ordinaria de control con la intervención del Congreso en relación con el estado de alarma. La redacción final no altera demasiado este presupuesto. En su momento, algunos vieron en el compromiso adquirido por el Congreso una conquista parlamentaria. De nuevo, rige la confusión. Pero, con todo, lo más inquietante es que de esta normativa parece deducirse que es el Gobierno quien determina la forma y "cantidad" del control. El Parlamento renuncia a su iniciativa en esta materia y acepta aquello que el Gobierno tiene a bien conceder. De acuerdo con el citado artículo 14 ¿hay que entender que el Parlamento se comprometía a no solicitar la comparecencia ni del Ministro de Sanidad ni del Presidente del Gobierno fuera de los términos allí establecidos? En principio, la respuesta parece afirmativa. Cuestión diferente es que, obviamente, el Congreso, algunas de las formaciones políticas que lo integran, hayan alterado ese ritmo. Pero ello no resta gravedad al axioma que subyace a este planteamiento. Para el Gobierno, y para el propio Congreso, es al primero a quién corresponde determinar cómo se ejerce el control. Evidentemente, una conclusión aún más grave cuando se trata de determinar el control en una situación de poder excepcional que exigiría de un Parlamento reforzado. Siempre cabe reprochar a un Gobierno que no sea respetuoso con el Parlamento. Pero es mucho más grave que el propio Parlamento no se respete a si mismo. De nuevo, el Congreso de los Diputados demuestra tener en poca estima el ejercicio de sus funciones. No se puede llegar a otra conclusión si a esta aceptación de las reglas del juego sobre el control ordinario se suma la aceptación de los seis meses de prórroga.

Junto a todo lo anterior, no puede obviarse el hecho de que durante el mes de enero de 2021, en un momento particularmente grave de la pandemia y bajo el estado de alarma, el Congreso activase el periodo vacacional y sólo celebrase dos sesiones de Diputación Permanente. La primera, el 25 de enero para dirimir una serie de solicitudes de comparecencias presentadas por la oposición y otra el 28 de enero para proceder a convalidar cinco reales decretos-leyes y realizar el debate de totalidad de la reforma de la LOPJ. Si bien es cierto que dos de esos decretos-leyes contenían medidas de apoyo a sectores afectados por la pandemia, ello no significa nada para el juicio que las dinámicas de la función de control merecen durante esta crisis. Más, creo que cuando menos es sorprendente que dada la situación, el Congreso no habilitase todo el periodo de sesiones para, al menos, la sustanciación de iniciativas relacionadas con la crisis. Una vez más, se manifiesta un Parlamento de perfil bajo, que lejos de ocupar el espacio que le corresponde y necesita la sociedad, se limita a 
servir de órgano gestor de aquellas iniciativas del Gobierno que necesitan de su participación (Sáenz, 2021).

Finalmente, una última circunstancia debe ser traída a colación para explicar la debilidad del control parlamentario durante la pandemia. En este caso, no se trata de una mala práctica u omisión. Me refiero al modelo de gestión territorial de la pandemia que establecía el decreto del segundo estado de alarma. Como es sabido, de acuerdo con el mismo, la gestión se delegaba en los Presidentes de las Comunidades Autónomas. Inevitablemente, ello repercutía en el control del estado de alarma. Atribuida la gestión a los ejecutivos autonómicos, lógicamente el núcleo del control recaía en los correspondientes Parlamentos. Una aproximación benevolente podría encontrar en ello explicación a la sustancial inacción del Congreso de los Diputados. Los Parlamentos habrían sustituido al Congreso en esta función. Ello podría haber sido así, siempre con el importante matiz de la menor capacidad objetiva de estas instituciones para realizar un control eficaz. Pero más bien el resultado ha sido la difuminación del control. La responsabilidad sobre la gestión de la pandemia se situó en una zona gris a la que no llegó ni el Congreso ni los Parlamentos autonómicos.

Esta debilidad global del control parlamentario se ratifica si se recuerda lo sucedido con lo acordado por las diversas "comisiones de reconstrucción" que se crearon tanto en el Estado como en diversas Comunidades Autónomas. Estas comisiones fueron celebradas y anunciadas con todos los altavoces posibles. En ellas participaron fuerzas políticas y agentes sociales y, en la mayoría de los casos, se alcanzaron acuerdos si no unánimes, sí muy amplios. Pues bien, hasta la fecha, ni los distintos ejecutivos han dado cuenta del cumplimiento de los objetivos allí fijados ni desde los distintos Parlamentos se ha solicitado esa rendición de cuentas. Por supuesto, tampoco se ha realizado la auditoria demandada de forma generalizada por los científicos que comparecieron y que la estimaban imprescindible para evitar errores. El impulso de esta tarea de revisión de lo sucedido era, es, una de las tareas más relevantes que cabe atribuir al Parlamento en relación con lo sucedido. Una vez más, no es posible exponer resultados al respecto.

\section{Señales preocupantes. El Parlamento y las líneas rojas}

La debilidad de la función legislativa, muy en particular la deriva del uso del Decreto-Ley y de la función de control no son novedad. Se lleva mucho tiempo denunciando estas circunstancias. En todo caso, se puede afirmar que lo sucedido durante los últimos meses refleja una aceleración del deterioro del proceso. Deterioro que sucede en un tiempo que exigía del Parlamento lo mejor de sí mismo. Por ello mismo, era preciso detenerse en las dos funciones más paradigmáticas del Parlamento. Pero no son las únicas señales preocupantes que nos depara este tiempo. Más allá del ejercicio de una determinada función, han sucedido una serie de hechos que son inquietantes, incluyendo alguno que supone quebranto de reglas que hasta ahora parecían indiscutibles. Si bien sería posible realizar una relación más amplia, me voy a detener a exponer algunas de las circunstancias que creo mejor ilustran un estado de situación poco halagüeño. En todo caso, más allá de la relevancia que cada uno de ellos puede tener aisladamente considerado, lo esencial es comprenderlos en su suma, como expresión de un ambiente de erosión de elementos básicos de la Institución y de los fundamentos que la sustentan.

En primer lugar, cabe referirse a alguna de las decisiones adoptadas durante la pandemia. Es obvio que muchas de ellas aun siendo poco ortodoxas 
o, directamente, irregulares, pudieron estar justificadas por las especiales circunstancias del momento, especialmente durante el primer mes de vigencia del estado de alarma (VV.AA., 2020; VV.AA., 2021). Con todo, alguna merece ser destacada por ser signo de debilidad política del Parlamento. Y otras deben ser traídas a colación por ser de más difícil justificación o por el riesgo que pueden conllevar como precedente.

Ya hubo ocasión de aludir a la suspensión de la actividad parlamentaria, decretada durante algún tiempo en la mayoría de las Cámaras y que sólo puede entenderse como una reacción impulsiva al desconcierto de los primeros momentos. Pero si ello pudo ser hasta comprensible en los primeros días, tal y como demuestra la tampoco ejemplar experiencia comparada (Koëlling, 2020; Guerrero, 2020: 200-215), no lo es que se extendiese en el tiempo, hasta el extremo de que el Senado estuviese prácticamente paralizado durante casi un mes. En este punto, es importante subrayar que más allá de la dejación de funciones esenciales para el sistema democrático, la imagen de los Parlamentos cerrados 0 , incluso, con una mínima presencia, alejaba a la Institución del carácter "esencial" que tiene. En mi opinión, se debió hacer un mayor esfuerzo de presencialidad, en paralelo a un nítido mensaje de "esencialidad" de la actividad parlamentaria. Las dificultades eran objetivas. Pero, con todas las cautelas precisas, se debió intentar impedir la imagen de unos Parlamentos cerrados o con un funcionamiento bajo mínimos ${ }^{5}$.

Ningún Parlamento tenía un marco normativo adecuado para una situación como la que se vivió en particular durante los meses de marzo y abril de 2021. De forma súbita, y al margen de la consideración precedente, las condiciones ordinarias de desenvolvimiento de la Institución se veían profundamente alteradas. Había que mantener el trabajo parlamentario sin poder asegurar la presencia de Diputados o Senadores. Incluso, restringiéndoles obligatoriamente el acceso a las Cámaras. Como se ha visto, el presupuesto sobre el que trabajaron la totalidad de los Parlamentos fue el de o bien no era posible la presencialidad o bien solamente se podía asegurar a una parte muy reducida de sus miembros. Como mal menor se imponía acudir a la tecnología para buscar en la misma, fórmulas que permitiesen solventar esta situación. Inmediatamente, hay que decir que en general se realizó con éxito un esfuerzo extraordinario. Tampoco los medios tecnológicos de los que se disponía estaban adaptados a esta situación y, sin embargo, en un escaso periodo de tiempo se pudo comenzar a desarrollar un trabajo "virtual" que poco a poco a permitió a los parlamentarios desarrollar su quehacer. La pregunta obligada es cómo se desarrolló ese trabajo y bajo qué sustento normativo. No es objeto de estas páginas desarrollar este punto, sobre el que ya existe notable bibliografía (VV.AA., 2020; VV.AA., 2021). Sí lo es poner de manifiesto las cuestiones que se consideran más delicadas bien por su posible relevancia como precedentes bien por su manifiesta "heterodoxia".

La imposibilidad de convocar a todos los miembros de la Institución conllevó de forma inmediata una drástica reducción de la actividad. La constatación de que esa situación no podía mantenerse por mucho tiempo y que la epidemia seguía viva, obligó a mirar a posibles fórmulas alternativas. Como es natural, el Congreso de los Diputados fue la primera Cámara obligada a reaccionar. En su caso, la propia declaración del estado de alarma le exigía desarrollar un mínimo

5 Se puede alegar que el Parlamento debía ser ejemplar en relación con la gravedad del momento y ser un ejemplo de las restricciones a la circulación que se impusieron al conjunto de los ciudadanos. Y, en general, creo que muchos Parlamentos se preocuparon más por transmitir esta imagen que por hacer notar a la ciudadanía que el quehacer parlamentario, siempre esencial, aún lo era más en esas circunstancias. 
de actividad. Poco a poco, otros Parlamentos fueron recuperando un cierto ritmo de actividad, si bien de forma desigual. Para poder hacerlo, manteniendo las limitaciones de presencia, había tres fórmulas: voto telemático, voto delegado y realización de sesiones virtuales. Hasta la fecha, sólo algún Reglamento contemplaba la posibilidad del voto telemático, pero anudando el mismo a causas tasadas y en las que no tenía cabida la situación que se vivía. Como es obvio, el presupuesto constitucional en juego era de la máxima relevancia. Junto al adecuado ejercicio de las funciones parlamentarias, se encontraba la necesidad de garantizar el ejercicio de los derechos inherentes al "ius ad officium" de los parlamentarios. Al objeto de resolver esta situación, cada Parlamento ha actuado de una manera, si bien, lógicamente, se pueden encontrar similitudes y, en algún caso, coincidencias. Prescindiendo de un análisis detenido de las distintas soluciones aportadas y dado el objeto de estas páginas, quiero destacar las circunstancias que estimo no debieran normalizarse y que, ya en sí mismas fueron dudosas, por más que en algún momento pudieran llegar a ser comprensibles.

La primera de ellas es la generalización de la aprobación de normas que muchas veces no es que no tuviesen amparo reglamentario sino que, directamente, contradecían el Reglamento. Normas que, hay que insistir, se referían a cuestiones esenciales directamente relacionadas con los derechos más básicos de los Diputados. De nuevo, es preciso el matiz e indicar que aquello que pudo ser comprensible durante las primeras urgencias, pronto no lo fue. Habilitada la celebración de sesiones plenarias, parece que hubiese sido razonable pensar en una modificación de los reglamentos que diese una mínima cobertura normativa a las decisiones que pudiesen adoptar otros órganos (Garrido Mayol, 2021: 150-160). Aunque es cierto que no es positivo legislar en "caliente" (García Escudero, 2020: 25), esta cautela debe ceder cuando se incurre en decisiones contra legem. La larga extensión en el tiempo de la pandemia, con casi nueve meses de vigencia del estado de alarma, refuerza esa impresión. No era necesario incorporar una solución definitiva. Bastaba con establecer un mínimo de certeza y ortodoxia jurídica ${ }^{6}$. Esta situación de, en el mejor de los casos, confusión normativa, se encuentra generalizada. No es positivo por lo que supone en sí misma. Pero aún resulta más preocupante por lo que tiene de precedente, por lo que puede suponer de relativización del marco que impone el Reglamento. La tentación de abrir vías "imaginativas" para su interpretación, como inmediatamente se verá, puede estar abierta.

Una segunda consideración, directamente ligada con la anterior tiene más de llamada de atención que de denuncia concreta. Necesariamente, durante estos meses se ha producido un vigoroso empoderamiento de los distintos órganos de las Cámaras y muy especialmente de las Presidencias. Ante la parálisis inicial, la necesidad de dar respuestas inmediatas, concentró en los mismos la adopción de decisiones de particular relevancia. No hay nada de extraño en ello. Además, las escasas dificultades que conllevaba la celebración de reuniones virtuales de los órganos colegiados, Mesa y Junta de Portavoces, incrementó su protagonismo. Pero, de nuevo, hay que advertir contra el riesgo de generalizar lo excepcional. Y la tentación puede ser importante. La larga duración de la pandemia facilita la generación de costumbre. Es más, como se

6 Así, resulta sorprendente que en agosto de 2021, el Congreso no hubiera afrontado esta reforma normativa. Hasta la fecha, se han sucedido tres proposiciones de reforma en este sentido (una fue rechazada; otra, retirada; y la última se encuentra pendiente de toma en consideración). 
indicó, es preciso revisar las decisiones adoptadas por estos órganos para, si es el caso, reconducirlas de acuerdo con las exigencias reglamentarias. Esta reflexión se debe extender a una de las consecuencias que desde la cultura parlamentaria más pueden preocupar. Me refiero al reforzamiento del poder de los Grupos frente a los Diputados individualmente considerados (Ripollés, 2021: 222). No creo una exageración decir que durante gran parte de este periodo, los Diputados como tales han sido testigos mudos y ciegos. Sus derechos han quedado restringidos a mínimos de acuerdo con lo establecido por los órganos rectores en aquiesciencia con los Grupos. Cualquier decisión relevante ha sido adoptada por los órganos directivos de los Grupos sin consulta a los Diputados. Se puede decir que no hay nada nuevo bajo el sol, que ese dominio de los Grupos sobre los parlamentarios individuales es la pauta tradicional. Es así. Pero durante estos meses las circunstancias han invitado a dar un paso más. La irrelevancia de los Diputados ha sido en muchas ocasiones, absoluta. Me he referido a la cultura parlamentaria. Se trata de eso. De evitar que lo sucedido durante estos meses contribuya a fortalecer una tendencia que es directamente contraria a las necesidades del Parlamento.

En este orden de advertencias, cabe por último referirse a los riesgos que conlleva la "normalización" del voto telemático y del propio "Parlamento virtual". Como se señalará en la conclusión, lo sucedido durante la pandemia no es un incidente coyuntural por grave que pueda considerarse. Ha enfrentado a la Institución a una situación insospechada y las respuestas exigidas se proyectarán una vez regrese la normalidad. Una de las cuestiones esenciales será medir el lugar que corresponde a ese espacio virtual. Adelanto que entiendo que no hay que cerrarse a la posibilidad de que se aprovechen las objetivas ventajas que este modelo de trabajar puede conllevar. Pero es una cuestión particularmente sensible y es preciso extremar la prudencia. La posible actividad virtual del Parlamento debería ser, en general, un plus de actividad. Por ejemplo, un instrumento para facilitar el desarrollo de comparecencias informativas con representantes de la sociedad civil, de modo que se favorezca la participación en sede parlamentaria. O para favorecer la relación del Diputado con su circunscripción. Y también puede ser instrumento idóneo para el desarrollo de las sesiones de algunos órganos de carácter casi rutinario, como las mesas de las Comisiones. Pero el Parlamento es deliberación y no hay deliberación sin presencia. Así, se debería mantener el carácter extraordinario del voto telemático. En relación con este extremo, una cuestión que transciende estas páginas pero que debe ser apuntada porque merece reflexión es la relativa a la figura del Diputado suplente. Cuando las dificultades de un Diputado para asistir se prolonguen por cierto tiempo, es una alternativa con ventajas objetivas frente al voto telemático.

Junto a estas cuestiones, hay que hacer mención a la concentración de la actividad de la Cámara en la Diputación Permanente, algo que sucedió en algunos Parlamentos autonómicos. Creo que en este caso se traspasó una línea de difícil justificación (en contra, Carrasco, 2020). Como se sabe, la Diputación Permanente es un órgano tradicional de nuestro derecho parlamentario que tiene la función de asegurar la permanencia de la Cámara en los dos supuestos en los que su funcionamiento se ve alterado: vacaciones parlamentarias y disolución de la Cámara. La Constitución, Estatuto de Autonomía y los Reglamentos parlamentarios establecen cuáles son las funciones que le corresponden en cada caso. La regla es la excepcionalidad. La Diputación Permanente, por definición, no sustituye totalmente al Pleno. No puede ejercer en plenitud sus funciones por una razón sencilla. Su composición es limitada y, en consecuencia, no es el reflejo de la composición de la Cámara. La mayoría de los Diputados, no pueden 
ejercer sus derechos. Por ello, cuando se trata de vacaciones parlamentarias, sus funciones son muy limitadas y se amplían cuando las Cámaras están disueltas. Así, es muy difícil aceptar su funcionamiento en supuestos que no sean los previstos por la Constitución y los Estatutos de Autonomía. Hay que insistir en que la suspensión de la actividad parlamentaria no era una solución necesaria. Más. Fue una alternativa equivocada. El Parlamento, como demuestra lo sucedido en el Congreso y en otras Cámaras autonómicas, podía seguir funcionando. En este caso, creo que no hay interpretación posible. Se contradice lo establecido por la Constitución y los Estatutos de Autonomía y se cercenan gravemente los derechos fundamentales de los Diputados. Es un buen ejemplo para acabar con el análisis de los problemas jurídicos planteados durante la pandemia. Sin duda, se necesitaba de la imaginación e ingeniería normativa y estas fueron usadas con generosidad. Pero todo tiene un límite. No se pueden contradecir normas esenciales y menos cuando afectan a derechos fundamentales. No sirve alegar la unanimidad de los Grupos ${ }^{7}$. Estos no pueden decidir sobre el ejercicio de los derechos de los Diputados (como estos no pueden renunciar al ejercicio de los mismos). $Y$ hay que volver a insistir en lo que de preocupante tienen este tipo de decisiones como precedente.

Si lo descrito hasta ahora debe matizarse en el contexto de la pandemia $y$, en general, preocupa sobre todo por lo que puede tener de precedente y afección a la cultura parlamentaria, lo sucedido en el Parlamento de Andalucía al desarrollar el denominado pacto antitransfuguismo es mucho más grave y viene a dar la razón sobre los riesgos derivados de empezar a relativizar normas y principios esenciales. El 28 de abril, el Parlamento aprobó una reforma de su Reglamento con la intención de adaptarlo al III Adenda al Pacto antitransfuguismo. La reforma fue aprobada con el voto a favor de los grupos parlamentarios Popular; Socialista; Ciudadanos; y Adelante Andalucía; abstención de Vox; y voto en contra de los Diputados no adscritos expulsados de Adelante Andalucía. El presupuesto es la denuncia del transfuguismo como una práctica antidemocrática que altera las mayorías expresadas por las urnas. La reforma introduce una definición de transfuguismo algo más que generosa: "se entiende en situación de transfuguismo a los Diputados que, traicionando al sujeto político (partido político, coalición electoral o agrupación de electores) que los presentó a las elecciones, hayan abandonado el mismo, hayan sido expulsados o se aparten del criterio fijado por sus órganos competentes". Es decir, cualquier Diputado que discrepe de "los órganos competentes" puede ser considerado tránsfuga ${ }^{8}$. Y si es así, la ira de los Dioses cae sobre él. Porque las consecuencias que la nueva normativa anuda a la declaración de tránsfuga son radicales. Prácticamente, se le extingue en su condición de Diputado. No hay exageración. Los diputados no adscritos no podrán ejercer ninguno de los derechos que corresponden a los grupos parlamentarios e, incluso, que en la Diputación Permanente y en las Comisiones se podrán establecer fórmulas "que repongan la representación política emanada del proceso electoral, incluida la del voto ponderado, sin que se produzca en ningún caso la sobrerrepresentación de los diputados no adscritos". La evidencia de las dificultades para encajar en los parámetros de la Constitución estas normas ya fueron observadas por la Letrada Mayor que

7 La decisión fue adoptada por unanimidad, aunque posteriormente el Grupo Parlamentario Socialista impugnó un Decreto-Ley por haberse aprobado en una sesión de la Diputación Permanente.

8 Así, se establece expresamente que puede ser considerado a "aquél que se separe del criterio político fijado por sus órganos competentes del Diputado o Diputada que concurrió por la candidatura de la que trae causa el Grupo Parlamentario". 
advirtió de que la reforma podría ser contraria a la prohibición del mandato imperativo y al derecho a ejercer libremente el cargo representativo en condiciones de igualdad. Además, no puede pasarse por alto su carácter profundamente regresivo y contrario al principio democrático (Fernández Esquer, 2021). La reforma transciende al Parlamento. Es un mensaje para cualquier militante. No cabe la discrepancia. Se exige una obediencia ciega. Lo paradójico es que semejante medida se adopta bajo la bandera de la regeneración democrática9 .

Frente a la objetiva necesidad de reivindicar el rol del Diputado como instrumento esencial para la revitalización del Parlamento, esta reforma más que debilitarlo, acaba por anularlo. La posición que los Grupos se adjudican es coherente con lo sucedido durante la pandemia. Es posible que no exista continuidad. Pero lo que es innegable es que esta reforma mantiene la idea de que los Grupos son todopoderosos y los Diputados figures inanes, sin personalidad ni derechos. Por lo demás, es preciso llamar la atención sobre la necesidad de reflexionar sobre el concepto de transfuguismo. Baste decir que el original Grupo Parlamentario de Adelante Andalucía se denomina hoy Unida Podemos por Andalucía, como reflejo de un evidente cambio político. Pues en el origen de la reforma está el rechazo de diversos Diputados, incluyendo quién encabezó la candidatura a ese giro. Hoy, en Unida Podemos se mantienen 6 Diputados. Once son diputados no adscritos, considerados "traidores". En un caso como éste ¿quién ejerce el transfuguismo?

Como un reflejo adicional del quebrantamiento de reglas que parecían infranqueables, hay que recordar lo sucedido en el Parlamento de Cataluña con motivo de la designación de Senadores autonómicos. Correspondiendo la designación de 8 Senadores, en virtud de los resultados electorales y de acuerdo con todos los precedentes, al Grupo Parlamentario de Vox le correspondía uno de esos Senadores. En virtud de la política de "cordón sanitario" contra este Grupo, adoptada por la mayoría de los Grupos de la Cámara, se decidió impedir que pudiese designar a un Senador. Para ello, se buscó una fórmula de acuerdo con la cual el último Senador no correspondía a esta formación. Hay que resaltar el orden de los factores. El presupuesto es que el mencionado Grupo no pudiese designar el Senador que parecía corresponderle. Más allá de la decisión que el Tribunal Constitucional adopte (el acuerdo del Parlamento fue recurrido por el Grupo Parlamentario), esta decisión supone una evidente ruptura de las reglas democráticas, quebrando la representación que correspondía a un Grupo Parlamentario y, en consecuencia, los derechos de sus electores. Se trata de una nueva manifestación de subordinación del Derecho (y de los principios democráticos) a la decisión política de turno.

Finalizo este punto haciendo mención a tres cuestiones que no por generales dejan de reflejar déficits significativos en el funcionamiento de la Institución. La primera de ellas es el escaso desarrollo de los principios de transparencia y participación, en particular, la transparencia. La epidemia ha sido una oportunidad magnífica para desarrollar este principio, haciendo de los portales de las distintas instituciones parlamentarias el núcleo de los recursos informativos sobre esta cuestión. Al menos, deberían haber organizado con claridad toda la información parlamentaria sobre la epidemia. Ello hubiese contribuido de manera significativa a que los ciudadanos se hiciesen una idea más adecuada de lo realizado por la institución y por cada uno de los grupos parlamentarios. Ningún Parlamento español ha adoptado una iniciativa parecida y el principio

9 Para explicar la reforma, el portavoz de Adelante Andalucía llegó a decir que con esta reforma "se robustece la calidad democrática de la Cámara andaluza". 
de transparencia sigue languideciendo en su triste incorporación a la Institución parlamentaria.

Una segunda reflexión merece el comportamiento de los distintos órganos rectores. Ya se avanzó algo. Pero no sólo se trata de advertir sobre los riesgos de que estos órganos se arroguen excesivos poderes, suplantando los procedimientos debidos. Es necesario llamar la atención sobre la debilidad general para reivindicar una posición propia frente a los ejecutivos. La posición de casi sumisión no es nueva. Pero en este caso se ha llegado a un extremo que los ha dejado en evidencia. La razón es sencilla. La gravedad de las circunstancias exigía que el Parlamento tuviese un perfil propio. No hay mejor ejemplo que el plazo de seis meses para la prórroga del segundo estado de alarma. Hubiese sido más que deseable que se alzase la voz de la Institución, con independencia de su éxito o fracaso, para expresar la inconveniencia de semejante propuesta por el radical desapoderamiento de la Institución que ello conllevaba. No sucedió nada. Sólo silencio. Algo similar sucedió en la mayoría de los Parlamentos autonómicos. Si el Parlamento no se reivindica a sí mismo, no hay camino a recorrer.

Finalmente, se puede aludir a una cuestión que apenas ha sido tratada en nuestra doctrina. Me refiero a la ausencia de relaciones entre los distintos Parlamentos españoles. Es preciso insistir en que la realidad parlamentaria española es la suma del trabajo de diecinueve Cámaras, cada una en su posición y escala. Pero las distintas funciones parlamentarias y, muy particularmente, el control del poder son el resultado de la suma de su acción. De nuevo, las circunstancias de la pandemia sirven para poner en evidencia debilidades previas. Durante estos meses, la gestión de la pandemia ha exigido respuestas coordinadas de las distintas autoridades territoriales. Esa gestión debería haber tenido unos estándares mínimos comunes, fruto de la coordinación entre los distintos Parlamentos. Asimismo, también podrían haber sido la institución adecuada para la centralización de información, desarrollando el mencionado principio de transparencia parlamentaria. No se hizo y la radical divergencia de respuestas a los distintos problemas suscitados por la crisis es el mejor reflejo de esta carencia. El reparto del poder político en nuestro país exige la colaboración entre los distintos Parlamentos como condición para el mejor cumplimiento global de sus funciones.

\section{Reflexiones para un mañana que es presente}

Es momento de concluir. En las páginas que anteceden he querido dar cuenta de algunos hechos que tienen en común que son reflejo de la debilidad de la Institución parlamentaria. Algunos son ya antiguos, aunque se hayan podido agravar en los últimos meses y otros son más recientes. Todos coinciden en reflejar una paulatina erosión del respeto que se debe a la primera institución del Estado. No puede alegarse la pandemia como explicación. Si bien en algunos casos, esta circunstancia puede matizar algún juicio, muchos hechos son anteriores; otros no tienen nada que ver con la misma; y la mayoría de los que directamente se relacionan con ella, bien podrían haber sido modulados de una forma más respetuosa con la Institución. Para comprender lo que sucede, más eficaz resulta tener presente el clima general de deterioro institucional en el que se desenvuelve nuestro país desde hace ya demasiados años. Se traspasan con frecuencia líneas hasta ayer rojas y las reglas que delimitan el funcionamiento de las instituciones son ignoradas, si no quebradas, con demasiada naturalidad. Los hechos que se han denunciado no tienen que ver con la tradicional crisis del Parlamento. Se encuentran directamente relacionados con el deterioro del 
sistema institucional. Así, llamar la atención sobre los mismos debe entenderse como un mensaje que transciende los muros de la Institución parlamentaria. El estado de las instituciones es un buen reflejo de la salud general de un país. Como es de sobra conocido, la de las nuestras es manifiestamente mejorable. Sólo un cambio profundo en la actitud de los distintos sujetos políticos podría trasladar un cierto halo de esperanza de cara al futuro. Inevitablemente, hoy hay que ser pesimista.

No se trata de reiterar, ni siquiera sintéticamente, lo expresado en las páginas anteriores. En estas líneas conclusivas sólo quiero advertir sobre alguna cuestión que considero de particular importancia. La primera de ellas es la que hace referencia a lo que se ha denominado "cultura parlamentaria". El Parlamento, como cualquier institución, se desenvuelve sobre los fundamentos y anclajes que le proporciona un poso formado por el legado histórico y los valores que inspiran a aquellos que protagonizan su funcionamiento. No creo que sea exagerado decir que hoy esos cimientos se encuentran seriamente debilitados. Si es cierto que esa cultura lleva décadas no siendo lo suficientemente fuerte como para situar con éxito a la Institución en el lugar que le corresponde, no lo es menos que durante los últimos años se aprecia una objetiva aceleración de su erosión. La razón es doble. Por una parte, la situación general del sistema institucional y el paulatino desapego en relación con reglas esenciales del Estado de derecho. Por otra, la posición de los distintos sujetos parlamentarios en relación con la Institución. Su tradicional desapego se ha acentuado hasta el extremo de que casi cualquier otro interés político se impone a sus deudas como miembros de la institución representativa. Hoy, nadie defiende al Parlamento. El Parlamento son sus Diputados y los que estos quieren que sea. Si los Diputados no otorgan a la Institución una posición relevante entre sus preocupaciones, no habrá nada que hacer, por más que se puedan mejorar normas y procedimientos 0 incrementar los medios de la Institución.

En segundo lugar, y ligado a lo anterior, cabe realizar una reflexión sobre el papel que corresponde desempeñar a los órganos rectores de la Institución, Presidencia y Mesa. Como es sabido, en los dos casos sus funciones transcienden la política partidista para asumir la dirección y representación de la Cámara. Por supuesto, ello no significa que la política no esté presente en sus acciones. Sería absurdo pretender lo contrario. Pero los intereses de partido no pueden llegar a eliminar de hecho su función radical, la defensa de la Institución y de su rol en el sistema político. Desde que Gregorio Peces Barba renunciase a votar para objetivar el ejercicio de su cargo hasta hoy ha pasado mucho tiempo y todo ha cambiado en relación con la visión del papel de los órganos rectores. Por mucho que se pueda considerar que el gesto de Peces Barba fuese un brindis al sol, ya que su voto no era necesario para su partido, no cabe desconocer lo que ese gesto tenía de reflejo de una determinada concepción de su rol. Desde entonces y casi abruptamente, se fue diluyendo ese papel institucional hasta no haber reparos en trasladar la imagen de no ser sino un fiel reflejo de las distintas posiciones partidistas y, en su caso, de la voluntad del Gobierno. Creo que lo sucedido durante la pandemia en el Congreso de los Diputados es el reflejo más radical de ello, si bien los antecedentes, y con presidencias de todos los signos políticos, no estaban muy lejos. De nuevo, hay que advertir que no se cae en la ingenuidad. Es inevitable, y coherente con las reglas del sistema, que incluso en el ejercicio de tareas institucionales, los órganos de gobierno se orienten de acuerdo con criterios de partido. El problema se encuentra en las situaciones límite, en esas decisiones que suponen una quiebra objetiva de los principios esenciales de la Institución o que limitan seriamente el ejercicio de sus funciones. El ejemplo de la prórroga del estado de alarma por 
seis meses es elocuente. En una situación similar, por más que se exija desde el poder ejecutivo (o desde la oposición), se deben anteponer los intereses de la Cámara. Nunca ha sido así, pero durante la pandemia ha quedado demasiado en evidencia. Hasta el punto de que hoy resulta obligado volver a plantearse su rol y condiciones de ejercicio de sus funciones.

Finalmente, es preciso advertir contra los riesgos de la unanimidad. La unanimidad es el caballo de Troya del derecho parlamentario. Hasta el extremo de que bien puede argumentarse que su valor en la práctica parlamentaria diluye la juridicidad de las normas parlamentarias o, al menos, la matiza severamente. Si bien cabe aceptar su utilidad como criterio para adoptar decisiones incluso contra la letra de la norma, inmediatamente hay que señalar que ello no puede suponer un cheque en blanco y que hay límites infranqueables, en particular los referidos a las decisiones relacionadas con derechos fundamentales o con principios esenciales de la Institución. Es preciso recordarlo hoy cuando las circunstancias han provocado que se hayan adoptado decisiones que en condiciones normales hubiesen resultado inimaginables. El largo tiempo transcurrido desde que se inició la pandemia, la todavía vigencia de la misma y la fuerza de la rutina para convertir lo extraordinario en ordinario, obligan a advertir que la unanimidad no es suficiente para contradecir reglas, principios y procedimientos previstos reglamentariamente. Si se desea incorporar nuevas formas de proceder, deberán reformarse las normas y siempre con el límite que implican las reglas esenciales de funcionamiento de la institución parlamentaria.

En relación con este punto, es preciso advertir sobre lo sucedido en el Parlamento de Andalucía. En este caso, se ha generado una nueva unanimidad, la resultante de excluir a los denominados tránsfugas. Como se advirtió, ello no puede nunca conllevar la vulneración de derechos esenciales ni alterar las reglas esenciales de la representación como las relativas al voto. Todo ello coincide en una nueva señal de alarma para la Institución. Lo sucedido durante los últimos meses ha reforzado aún más el papel de los grupos parlamentarios. La tentación de consolidar esta posición es evidente, como demuestra la reforma del Reglamento del Parlamento de Andalucía. Se trata de la dirección contraria a la que es preciso adoptar si se quiere reforzar la Institución. Si se acaba por anular al Diputado individual, el Parlamento se verá abocado a abocarse por su propia necesidad en su actual configuración.

\section{Bibliografía}

Aragón Reyes, M. (2016). Uso y abuso del Decreto-Ley. Una propuesta de reforma constitucional. Madrid: lustel.

Aragón Reyes, M. (2017). Legislatura fallida e investidura convulsa. Análisis y consecuencias, Revista Española de Derecho Constitucional, 109, 15-34. Disponible en: DOI: https://doi.org/10.18042/cepc/redc.109.01

Astarloa Huarte-Mendicoa, I. (2017). El Parlamento moderno. Importancia, descrédito y cambio. Madrid: Fundación Alonso Martín Escudero-lustel.

Carmona Contreras, A. (1997). La configuración constitucional del Decreto-Ley. Madrid: Centro de Estudios Políticos y Constitucionales.

Carrasco Durán, M. (2020). El Parlamento ante la pandemia de la Covid 19: el caso del Parlamento de Andalucía. Revista "Cuadernos Manuel Giménez Abad", Extraordinario 8, 28-36. Disponible en: https://www.fundacionmgimenezabad.es/sites/default/files/Publicar/publicaciones/documentos/ monografia 8 junio 2020 1.pdf 
Fernández Esquer, C. (2021). Andalucía refuerza el dirigismo de las cúpulas partidistas. Disponible en: https://agendapublica.es/ andalucia-refuerza-el-dirigismo-de-las-cupulas-partidistas/

García Escudero. P. (2020). Actividad y funcionamiento de las Cortes Generales durante el estado de alarma por Covid-19. Revista "Cuadernos Manuel Giménez Abad", Extraordinario 8, 18-27. Disponible en: https://www.fundacionmgimenezabad.es/sites/default/files/Publicar/publicaciones/documentos/monografia_8 junio_2020_1.pdf

García Roca, J. (2017). ¿Puede rechazar el control parlamentario un gobierno en funciones? En E. Aranda Álvarez (coord.), Lecciones constitucionales de 314 días con el Gobierno en funciones (pp. 131-150). Valencia: Tirant Lo Blanch.

García Rocha, M.P. (2020). El procedimiento legislativo en lectura única. Madrid: Congreso de los Diputados.

Garrido López, C. (2021). Decisiones excepcionales y garantía jurisdiccional de la Constitución. Madrid: Marcial Pons.

Garrido Mayol, V. (2021). La Covid 19 también llegó al Parlamento: la excepcionalidad como excusa al Estado de derecho. Corts: Anuario de derecho parlamentario, Extraordinario 34, 139-174. Disponible en: https://www.cortsvalencianes. es/sites/default/files/media/file author/corts 34 02 III 1 139-174.pdf

Greciet, E. (2012). El Parlamento como problema y como solución. Asamblea, Revista parlamentaria de la Asamblea de Madrid, 26, 235-298. Disponible en: https://www.asambleamadrid.es/documents/20126/64823/R.26. Esteban Greciet Garcia.pdf/40ffaOc0-710b-564c-5bc5-e8e56bf4a2ea

Guerrero Vázquez, P. (2020). El sistema parlamentario británico ante la Covid-19 Revista "Cuadernos Manuel Giménez Abad", Extraordinario 8, 200-215. Disponible en: https://www.fundacionmgimenezabad.es/sites/default/ files/Publicar/publicaciones/documentos/monografia 8 junio 2020 1.pdf.

Guillén López, E. (2019). Repensando la forma de gobierno. Constitucionalismo, democracia y parlamentarismo en contextos postnacionales. Madrid: Marcial Pons-Fundación Manuel Giménez Abad.

Kölling, M. (2020). El Bundestag y el Bundesrat alemán en tiempos de Covid 19. Revista "Cuadernos Manuel Giménez Abad", Extraordinario 8, 189-199. Disponible en: https://www.fundacionmgimenezabad.es/sites/default/ files/Publicar/publicaciones/documentos/monografia 8 junio 2020 1.pdf

Paniagua, J.L. (2012). España: un parlamentarismo racionalizado de Corte Presidencial. En J. Lánzaro, (coord.), Presidencialismo y parlamentarismo. América Latina y Europa Meridional: Argentina, Brasil, Chile, España, Italia, México, Portugal y Uruguay (pp. 225-268). Madrid: Centro de Estudios Políticos y Constitucionales.

Reviriego Picón, F. (2017). La permanencia en funciones del gobierno; algunas reflexiones tras 314 días de interinidad. En E. Aranda Álvarez (coord.), Lecciones constitucionales de 314 días con el Gobierno en funciones (pp. 151-176). Valencia: Tirant Lo Blanch.

Rico, C. (2013) El debate parlamentario: ¿Deliberación o agonismo? Disponible en: https://aecpa.es/files/view/pdf/congress-papers/11-0/676/

Ripollés Serrano, M.R. (2017). Control en funciones y control parlamentario. En E. Aranda Álvarez (coord.), Lecciones constitucionales de 314 días con el Gobierno en funciones (pp. 103-126). Valencia: Tirant Lo Blanch.

Ripollés Serrano, M.R. (2021). ¿Un Parlamento por delegación? La experiencia de una Comisión permanente del Congreso de los Diputados durante la pandemia por la Covid 19. Corts: Anuario de derecho parlamentario, Extraordinario 34, 203-224. Disponible en: https://www.cortsvalencianes. es/sites/default/files/media/file author/corts 3402 III 3 203-224.pdf 
Sáenz Royo, E. (2021). La incapacidad del Congreso durante la pandemia. Disponible en: https://agendapublica.es/la-incapacidad-del-congreso-en-la-pandemia/

Tudela Aranda, J. (2020a), Crisis política (y social) y Derecho Constitucional. Teoría y Realidad Constitucional, 46, 173-210. Disponible en: https://doi. org/10.5944/trc.46.2020.29109

Tudela Aranda, J. (2020b). El Parlamento en tiempos críticos. Nuevos y viejos temas del Parlamento. Madrid: Marcial Pons-Ubijus.

Visiedo, F., (2017), Un gobierno en funciones, no un Parlamento en funciones. En E. Aranda Álvarez (coord.), Lecciones constitucionales de 314 días con el Gobierno en funciones (pp. 177-202). Valencia: Tirant Lo Blanch.

VV.AA. (2017). Lecciones constitucionales de 314 días con el Gobierno en funciones (E. Aranda Álvarez (coord.). Valencia: Tirant Lo Blanch.

VV.AA. (2020). El Parlamento ante la Covid-19 (J. Tudela Aranda (coord.), Fundación Manuel Giménez Abad, Cuadernos Monografías, 8.

VV.AA. (2021). El funcionamiento del Parlamento ante la crisis sanitaria, Corts: Anuario de derecho parlamentario, Extraordinario 34. 